University of Nebraska - Lincoln

DigitalCommons@University of Nebraska - Lincoln

Faculty Papers and Publications in Animal

Science

Animal Science Department

2008

\title{
A New Heat Load Index for Feedlot Cattle
}

J. B. Gaughan

University of Queensland, j.gaughan@uq.edu.au

Terry L. Mader

University of Nebraska-Lincoln, tmader1@unl.edu

S. M. Holt

Hubbard Feeds Inc., Mankato, MN

A. Lisle

University of Queensland, Gatton, Queensland, Australia

Follow this and additional works at: https://digitalcommons.unl.edu/animalscifacpub

Part of the Animal Sciences Commons

Gaughan, J. B.; Mader, Terry L.; Holt, S. M.; and Lisle, A., "A New Heat Load Index for Feedlot Cattle" (2008). Faculty Papers and Publications in Animal Science. 613.

https://digitalcommons.unl.edu/animalscifacpub/613

This Article is brought to you for free and open access by the Animal Science Department at DigitalCommons@University of Nebraska - Lincoln. It has been accepted for inclusion in Faculty Papers and Publications in Animal Science by an authorized administrator of DigitalCommons@University of Nebraska - Lincoln. 


\title{
A new heat load index for feedlot cattle ${ }^{1}$
}

\author{
J. B. Gaughan, ${ }^{2}$ T. L. Mader, $\dagger$ S. M. Holt, $\neq$ and A. Lisle*
}

*The University of Queensland, Gatton, Queensland, Australia, 4343; †Haskell Agricultural Laboratory, University of Nebraska-Lincoln, 57905866 Rd., Concord 68728; and $\ddagger$ Hubbard Feeds Inc.,

PO Box 8500, Mankato, MN 56002-8500

\begin{abstract}
The ability to predict the effects of extreme climatic variables on livestock is important in terms of welfare and performance. An index combining temperature and humidity (THI) has been used for more than 4 decades to assess heat stress in cattle. However, the THI does not include important climatic variables such as solar load and wind speed (WS, $\mathrm{m} / \mathrm{s}$ ). Likewise, it does not include management factors (the effect of shade) or animal factors (genotype differences). Over 8 summers, a total of 11,669 Bos taurus steers, 2,344 B. taurus crossbred steers, 2,142 B. taurus $\times$ Bos indicus steers, and 1,595 B. indicus steers were used to develop and test a heat load index (HLI) for feedlot cattle. A new HLI incorporating black globe (BG) temperature $\left({ }^{\circ} \mathrm{C}\right)$, relative humidity $(\mathrm{RH}$, decimal form), and WS was initially developed by using the panting score (PS) of 2,490 Angus steers. The HLI consists of 2 parts based on a BG temperature threshold of $25^{\circ} \mathrm{C}$ : $\mathrm{HLI}_{\mathrm{BG}>25}=8.62+(0.38 \times \mathrm{RH})+(1.55 \times \mathrm{BG})-(0.5 \times$ $\mathrm{WS})+\mathrm{e}^{(2.4-\mathrm{WS})}$, and $\mathrm{HLI}_{\mathrm{BG}<25}=10.66+(0.28 \times \mathrm{RH})+$ $(1.3 \times \mathrm{BG})-\mathrm{WS}$, where $\mathrm{e}$ is the base of the natural logarithm. A threshold HLI above which cattle of different genotypes gain body heat was developed for 7 genotypes. The threshold for unshaded black $B$. taurus steers was 86 , and for unshaded B. indicus (100\%) the
\end{abstract}

threshold was 96. Threshold adjustments were developed for factors such as coat color, health status, access to shade, drinking water temperature, and manure management. Upward and downward adjustments are possible; upward adjustments occur when cattle have access to shade $(+3$ to +7$)$ and downward adjustments occur when cattle are showing clinical signs of disease $(-5)$. A related measure, the accumulated heat load (AHL) model, also was developed after the development of the HLI. The AHL is a measure of the animal's heat load balance and is determined by the duration of exposure above the threshold HLI. The THI and THI-hours (hours above a THI threshold) were compared with the HLI and AHL. The relationships between tympanic temperature and the average HLI and THI for the previous $24 \mathrm{~h}$ were $\mathrm{R}^{2}=0.67, P<0.001$, and $\mathrm{R}^{2}=0.26$, $P<0.001$, respectively. The $\mathrm{R}^{2}$ for the relationships between HLI or AHL and PS were positive (0.93 and 0.92 for HLI and AHL, respectively, $P<0.001$ ). The $\mathrm{R}^{2}$ for the relationship between THI and PS was 0.61 ( $P$ $<0.001)$, and for THI-hours was $0.37(P<0.001)$. The HLI and the AHL were successful in predicting PS responses of different cattle genotypes during periods of high heat load.

Key words: bioclimatic index, beef cattle, feedlot, heat stress

(c)2008 American Society of Animal Science. All rights reserved.

J. Anim. Sci. 2008. 86:226-234 doi:10.2527/jas.2007-0305

\section{INTRODUCTION}

Occasional periods of excessive ambient heat affect the growth performance and welfare of feedlot cattle. The temperature-humidity index (THI; Thom, 1959) has been widely used as an indicator of thermal stress in livestock (Ingraham et al., 1974; Ibrahim et al., 1975;

\footnotetext{
${ }^{1}$ This study was funded by Meat Livestock Australia P/L (North Sydney, New South Wales, Australia). The authors would like to thank S. Lott, T. Byrne, and P. Binns of EA Systems P/L (Armidale, New South Wales, Australia), the management and staff at Katestone P/L (Brisbane, Queensland, Australia), and the commercial feedlots for their participation in this project.
}

Hahn and Mader, 1997; Gaughan et al., 1999), and the THI forms the basis of the Livestock Weather Safety Index (Livestock Conservation Incorporated, 1970). However, the THI has limitations because it does not account for solar radiation or wind speed (St-Pierre et al., 2003; Brown-Brandl et al., 2005b; Mader et al., 2006). Various THI have been developed by using dry bulb temperature in combination with wet bulb temperature, relative humidity, or dew point (Buffington et al.,

\footnotetext{
${ }^{2}$ Corresponding author: j.gaughan@uq.edu.au Received May 28, 2007.

Accepted September 17, 2007.
} 
1981; Baeta et al., 1987; Roseler et al., 1997). Recently, wind and solar radiation adjustments have been developed based on changes in respiratory dynamics (Mader et al., 2006) and on a respiration rate index using dry bulb temperature, relative humidity, wind speed, and solar radiation (Eigenberg et al., 2005).

Current indices do not account for the cumulative effects of heat load, natural cooling, or both. Cattle may accumulate heat during the day (the body temperature rises) and dissipate the heat at night. If there is insufficient night cooling, cattle may enter the following day with an accumulated heat load (AHL; Hahn and Mader, 1997). The THI-hours model was developed to account for the impact of intensity $\times$ duration on thermal status (Hahn and Mader, 1997). Similarly, St-Pierre et al. (2003) developed models using combinations of the maximum THI, daily duration of heat stress, and a heat load index (HLI). Neither model accounts for air movement or solar radiation.

Therefore, the objectives of this study were to develop and validate a new HLI for cattle based on respiratory dynamics and tympanic temperature. Heat load thresholds were also determined for different genotypes, and an AHL model was developed to predict the heat balance of cattle.

\section{MATERIALS AND METHODS}

The use of animals in this study was approved by The University of Queensland Animal Ethics Committee in accordance with the Queensland Animal Care and Protection Act and the Australian Code of Practice for the Care and Use of Animals for Scientific Purposes.

\section{HLI Development}

Data from 13 feedlots were used in this study. Ten of these data sets were obtained from Australia (9 commercial feedlots and 1 research feedlot) and 3 were obtained from research feedlots in the United States. The data collection periods for the commercial Australian feedlots were January to March 2000, 2002, 2004, 2005, and 2006. Data collection for the research feedlots occurred from January to February 2003 (Australia) and from July to August 2002, 2004, and 2005 (United States). These data were used to develop and evaluate the HLI.

Cattle $(n=2,490)$ for the initial data collection period (January to March 2000) were selected for consistency in terms of genotype (black Angus), days on feed (100 d as of January 1), BCS (4+; based on the Australian body condition score of $1=$ lean to $5=$ very fat), no access to shade, and sex (steers); this was the reference animal. The predominant breed across all feedlots for the post-2000 studies was Angus ( $=6,585)$. Sixteen additional genotypes, Brahman ( $\mathrm{n}=1,403)$, Santa Gertrudis $(\mathrm{n}=1,039)$, Hereford $(\mathrm{n}=1,011)$, Waygu $(\mathrm{n}=$ 894), Hereford $\times$ Angus $(\mathrm{n}=704)$, Hereford $\times$ Brahman $(\mathrm{n}=608)$, European-cross (with unidentified Bos taurus; $\mathrm{n}=587$ ), European-cross (with unidentified Bos indicus; $\mathrm{n}=429)$, Angus $\times$ Charolais $(\mathrm{n}=298)$, Charolais $(n=293)$, Santa Gertrudis $\times$ Charolais $(n=293)$, Shorthorn $(n=206)$, Droughtmaster $(n=192)$, Santa Gertrudis $\times$ Hereford $(n=191)$, Santa Gertrudis-cross (with unidentified B. indicus; $\mathrm{n}=190$ ), and Shorthorn $\times$ Hereford ( $\mathrm{n}=147)$, were used to evaluate the HLI. From these, 7 genotypic categories were defined: $B$. taurus (British), B. taurus (European), Waygu, and B. indicus $(25,50,75$, or $100 \%)$. Factors considered in the development of the heat load model included genotype, coat color, health status, access to shade, area of shade, days on feed, manure management, and drinking water temperature. Pen size, stocking rate, feed bunk space, water trough space, shade design, and area under shade were not standardized among feedlots.

The commercial feedlots ranged in capacity from 9,000 to 50,000 cattle. The Australian research feedlot had a capacity of 200 cattle. Two of the US research feedlots had capacities of 325 cattle and 1 had a capacity of 720 cattle. Across all feedlots, stocking densities varied from 12.5 to $22 \mathrm{~m}^{2} /$ animal. In feedlots that provided shade, the shaded areas varied from 1.1 to $5.3 \mathrm{~m}^{2} /$ animal (at 1200). Shade materials used included shade cloth (70 to $90 \%$ solar block) and steel (various combinations of open spacing between solid and open areas to solid shade). The height of the shade structures ranged from 2 to $5.4 \mathrm{~m}$. Manure depth $(\mathrm{mm})$ was measured at 5 feedlots (20 pens; 4,000 cattle). This was done by taking 5 measures from the front to the rear of a pen at approximately $15-\mathrm{m}$ intervals. Measures were made at the beginning, approximately midway, and at the end of the data collection period. Values were then averaged. Drinking water temperature was measured at 3 feedlots (6 pens; 1,080 unshaded Angus steers) at approximately $1000,1200,1400$, and 1600 on days when cattle were heat stressed. Water temperature was measured by using a thermistor attached to a data logger (YSI 400, Mini-Mitter, Sun River, OR).

Automated weather stations were located at each feedlot. At each location, air temperature $\left(\mathrm{T}_{\mathrm{a}},{ }^{\circ} \mathrm{C}\right)$, solar radiation $(\mathrm{W} / \mathrm{m})$, wind speed $(\mathrm{m} / \mathrm{s})$, relative humidity $(\%)$, and black globe $(\mathbf{B G})$ temperature $\left({ }^{\circ} \mathrm{C}\right)$ were recorded at 10-min intervals. Rainfall $(\mathrm{mm})$ was also recorded. From 2000 to 2002, the THI was calculated for each weather station by using the following equation: $\mathrm{THI}=(0.8 \times$ ambient temperature $)+\{[($ relative humid ity/100) $\times$ (ambient temperature -14.4$)]+46.4\}$ (adapted from Thom, 1959). In addition, THI-hours were calculated by using the method of Hahn and Mader (1997). After 2002, in addition to THI and THIhours, the new HLI and AHL units were calculated (see below for details).

Within each commercial data set, the panting scores (Table 1) of cattle were recorded for $54 \mathrm{~d}$. Cattle were assessed 3 times each day at approximately 0600, 1200, and 1600. Thus, approximately 162 observations were made per animal. During periods of extreme weather, observations were made at 2 -h intervals between 0600 
Table 1. Panting score, breathing condition, and the associated respiration rate ${ }^{1}$

\begin{tabular}{ll}
\hline \hline $\begin{array}{l}\text { Panting } \\
\text { score }\end{array}$ & \multicolumn{1}{c}{ Breathing condition } \\
\hline 0 & No panting. \\
1 & Slight panting, mouth closed, no drool, easy to see chest movement. \\
2 & Fast panting, drool present, no open mouth. \\
2.5 & As for 2, but occasional open mouth panting, tongue not extended. \\
3 & Open mouth and excessive drooling, neck extended, head held up. \\
3.5 & As for 3 but with the tongue out slightly and occasionally fully extended for short periods. \\
4 & Open mouth with tongue fully extended for prolonged periods with excessive drooling. Neck extended and head up. \\
4.5 & As for 4 but head held down. Cattle "breathe" from the flank. Drooling may cease. \\
\hline
\end{tabular}

${ }^{1}$ Modified from Mader et al. (2006).

and 1800. Panting score was the key physiological and behavioral factor used in the development of the HLI and in establishing the heat load thresholds. Mean panting score was calculated according to the following formula:

$$
\text { panting score }=\frac{\sum_{i=0}^{4.5} \mathrm{~N}_{\mathrm{i}} \times \mathrm{i}}{\sum_{i=0}^{4.5} \mathrm{~N}_{\mathrm{i}}},
$$

where $\mathrm{N}_{\mathrm{i}}=$ the number of cattle observed at panting score i.

Additional data collected at the research feedlots were respiration rates (15-min intervals; Australian facility) and panting scores at 2 -h intervals from 0600 to 1800 . Tympanic temperatures were recorded from cattle $(\mathrm{n}=90)$ at the US 720-capacity feedlot at 30-min intervals over three 6 -d heat waves, from 80 cattle at the US 325-capacity feedlots at 30-min intervals, and from 20 cattle at the Australian research feedlot at 15min intervals on four 5-d heat waves. Tympanic temperature was measured by using the procedure of Mader et al. (2002). The thermistors remained in the ear for a maximum of $7 \mathrm{~d}$.

\section{Development of Thresholds}

After development of the HLI, a threshold value for the reference animal was developed. The HLI value at which body heat is readily dissipated into the environment is influenced by a number of factors. The major nonclimatic factors that influence heat dissipation were identified, and HLI thresholds were determined for these factors. Data collected after the first study in 2000 were used to identify the major thresholds. The major thresholds were identified as genotype (B. taurus, $B$. indicus, and crossbred cattle), coat color (black, red, and white), health status, degree of acclimatization, access to shade, area of shade available, days on feed, depth of manure, and water trough temperature. The influence of previously mentioned factors on alleviating or contributing to heat load was assessed primarily on changes in mean panting score. Adjustments to the reference animal threshold (positive or negative) were made on the basis of $\geq 20 \%$ of the cattle in a pen having a panting score of $\geq 1$. This value was determined on the basis of the majority of reference cattle in a pen moving from a panting score of 1 to 2 very quickly when more than $20 \%$ of the cattle in a pen had a panting score of 1 .

\section{AHL Model Development}

Following the development and validation of the HLI, the AHL model was developed. The AHL is a 2-dimensional function incorporating time and animal heat balance (the amount of time the animal is exposed to an HLI above its threshold, the upper threshold). When this occurs, the animal is not dissipating sufficient body heat into the environment and therefore core body temperature increases above its normal range. Alternatively, if the HLI falls below the upper threshold, then the animal is able to dissipate body heat into the environment, and core body temperature will return to the normal range. The threshold value is genotype specific and is also affected by management factors such as access to shade and drinking water temperature. The upper threshold was defined as the HLI, where $\geq 20 \%$ of unshaded cattle had a panting score of $\geq 1$.

\section{Statistical Analysis}

Because of the uneven number of animals per pen within and across feedlots, all observational data were converted from the actual observation number to the proportion of animals in the pen. For statistical analysis, the percentages of cattle recorded for each panting score measure (within a feedlot, and then within a genotype across and within feedlots) were transformed to a normalized distribution by using a square root-arcsine transformation.

The HLI was developed by using regression analysis (PROC REG, RSREG; SAS Inst. Inc., Cary, NC). The regression analysis was used to determine the relationship between mean panting score (2,490 cattle, 403,380 observations) and climatic parameters (ambient temperature, relative humidity, wind speed, solar radiation, and BG temperature). Solar radiation and ambient temperature were eliminated from the model by the backward elimination procedure. 
Based on the statistical analysis of panting score $(4,200$ observations) and body temperature (3,148 observations) data of unshaded Angus steers $(n=190)$ at the research feedlots, the HLI was divided into 4 categories: 1) thermoneutral conditions, when the HLI is $<70.0 ; 2$ ) warm conditions, when the HLI is 70.1 to 77.0 ; 3) hot conditions, when the HLI is 77.1 to 86.0 ; and 4 ) very hot conditions, when HLI is $>86.0$. Accumulated heat load was divided into 5 categories: 1 ) thermoneutral conditions, when the AHL is $<1 ; 2$ ) mild conditions, when the AHL is 1 to $10 ; 3$ ) warm conditions, when the AHL is 10.1 to 20 ; 4) hot conditions, when the AHL is 20.1 to 50 ; and 5) very hot conditions, when the AHL is $>50$. These thresholds were identified by fitting polynomial equations by using PROC REG. The thresholds identified marked upward or downward shifts in panting score and body temperature of unshaded Angus steers.

The panting score data from the post-2000 studies were analyzed by using $\chi^{2}$ analysis and the PROC CORR, PROC NLIN, PROC SORT, PROC MIXED, PROC REG, and PROC GLM options of SAS. The models used were the effects of HLI, AHL, HLI category, AHL category, THI, and THI-hours on panting scores $(14,481$ cattle, $1,563,948$ observations). Pen effects were considered where the same genotype was in shaded and unshaded pens within a feedlot. Interactions among genotype, pen, time of day (0601 to $1200 ; 1201$ to 1700 ; 1701 to 0600), HLI, AHL, THI, and THI-hours were analyzed, and the effects of those individual variables on panting scores were determined. Statistical models for mean panting score included genotype $\times$ feedlot $x$ pen $\times$ HLI $\times$ time of day and genotype $\times$ feedlot $\times$ pen $\times$ AHL $\times$ time of day. The HLI $\times$ AHL category interactions on panting score was also investigated. Similar models were used for THI and THI-hours. Independent data sets comprising the 1,200 to 1,800 observations were used to validate the HLI, AHL, and threshold values.

Tympanic temperature data (3,148 observations) were analyzed by using Fourier frequencies. Each $30-$ min time point represented a proportion of a complete cycle. The linear regression model (PROC REG) used was as follows:

$$
\mathrm{Y}=\mathrm{B}_{0}+\mathrm{B}_{1} \sin (2 \pi \times \mathrm{h} / 24)+\mathrm{B}_{2} \cos (2 \pi \times \mathrm{h} / 24),
$$

where $\mathrm{h}=$ time in hours.

A fraction of a day (h/24) was multiplied by $2 \pi$, which translated the time into radians. Having both sine and cosine components allows the cycle to shift left or right, as required. The intercept $B_{0}$ estimates the average temperature around which the cycle oscillates.

When Fourier frequencies are fitted, the model becomes:

$$
\begin{aligned}
\mathrm{Y}= & \mathrm{B}_{0}+\mathrm{B}_{1} \sin (2 \pi \times \mathrm{h} / 24)+\mathrm{B}_{2} \cos (2 \pi \times \mathrm{h} / 24) \\
& +\mathrm{B}_{3} \sin (4 \pi \times \mathrm{h} / 24)+\mathrm{B}_{4} \cos (4 \pi \times \mathrm{h} / 24) .
\end{aligned}
$$

where $\mathrm{HLI}_{\mathrm{ACC}}=$ the actual HLI value at a point in time; $\mathrm{HLI}_{\text {Lower Threshold }}$ = the HLI threshold below which cattle in a particular class will dissipate heat (e.g., 77 for the

This equation adjusts the diurnal cycle by making the oscillations in tympanic temperature less symmetric.

The parameter associated with HLI in the regression models is thus the elevation in tympanic temperature for each "unit" of heat load. An increase of 10 in the HLI should result in an increase of $0.3^{\circ} \mathrm{C}$ in tympanic temperature.

\section{RESULTS}

\section{HLI}

Analysis of the panting score data determined that there was a $\mathrm{BG}$ temperature threshold $\left(25^{\circ} \mathrm{C}\right)$ above which panting score increased from 0 to 1 by $\geq 20 \%$ of the cattle. Two multiple regression models were developed by using the panting score data from unshaded Angus steers $(n=2,490)$. The first model (equation [4]) was a nonlinear regression model, which was applied when BG temperature was greater than $25^{\circ} \mathrm{C}$. The second linear model (equation [5]) was applied when BG temperature was less than $25^{\circ} \mathrm{C}$. Both models were developed by using relative humidity (in decimal form), BG temperature, and wind speed. All parameters were significant $(P<0.001)$.

$$
\begin{aligned}
\mathrm{HLI}_{\mathrm{BG}>25}= & 8.62+(0.38 \times \text { relative humidity }) \\
+(1.55 \times \mathrm{BG} \text { temperature })-(0.5 \times \text { wind speed })[4] & +\left[\mathrm{e}^{2.4-\text { wind speed }], \text { and }}\right. \\
\mathrm{HLI}_{\mathrm{BG}<25}= & 10.66+(0.28 \times \text { relative humidity }) \\
+ & (1.3 \times \mathrm{BG})-\text { wind speed }
\end{aligned}
$$

where $\mathrm{e}=$ the base of the natural logarithm (approximate value of $\mathrm{e}=2.71828$ ).

\section{AHL}

For the reference animal, the upper threshold at which the animal accumulates heat was established at HLI $=86$, and the lower threshold was 77. For a Brahman, the upper threshold was defined as HLI $=96$ (Table 2). Over a 24-h period, the AHL may be increasing or may be decreasing. However the AHL value does not fall below zero. A zero value indicates that the animal is in thermal balance. The following equation was used to calculate the AHL:

$$
\begin{gathered}
\text { If }\left[\mathrm{HLI}_{\mathrm{ACC}}<\mathrm{HLI}_{\text {Lower Threshold }},\right. \\
\left.\left(\mathrm{HLI}_{\mathrm{ACC}}-\mathrm{HLI}_{\text {Lower Threshold }}\right) / \mathrm{M}\right], \\
\text { If }\left[\mathrm{HLI}_{\mathrm{ACC}}>\mathrm{HLI}_{\mathrm{Upper} \text { Threshold }},\right. \\
\left.\left(\mathrm{HLI}_{\mathrm{ACC}}-\mathrm{HLI}_{\text {Upper Threshold }}\right) / \mathrm{M}, 0\right],
\end{gathered}
$$


Table 2. Animal (genotype, coat color, health status, acclimatization) and management (access to shade, days on feed, manure management, and drinking water temperature) adjustments (+ and - ) to the heat load index (HLI) threshold of the reference steer ${ }^{1}$

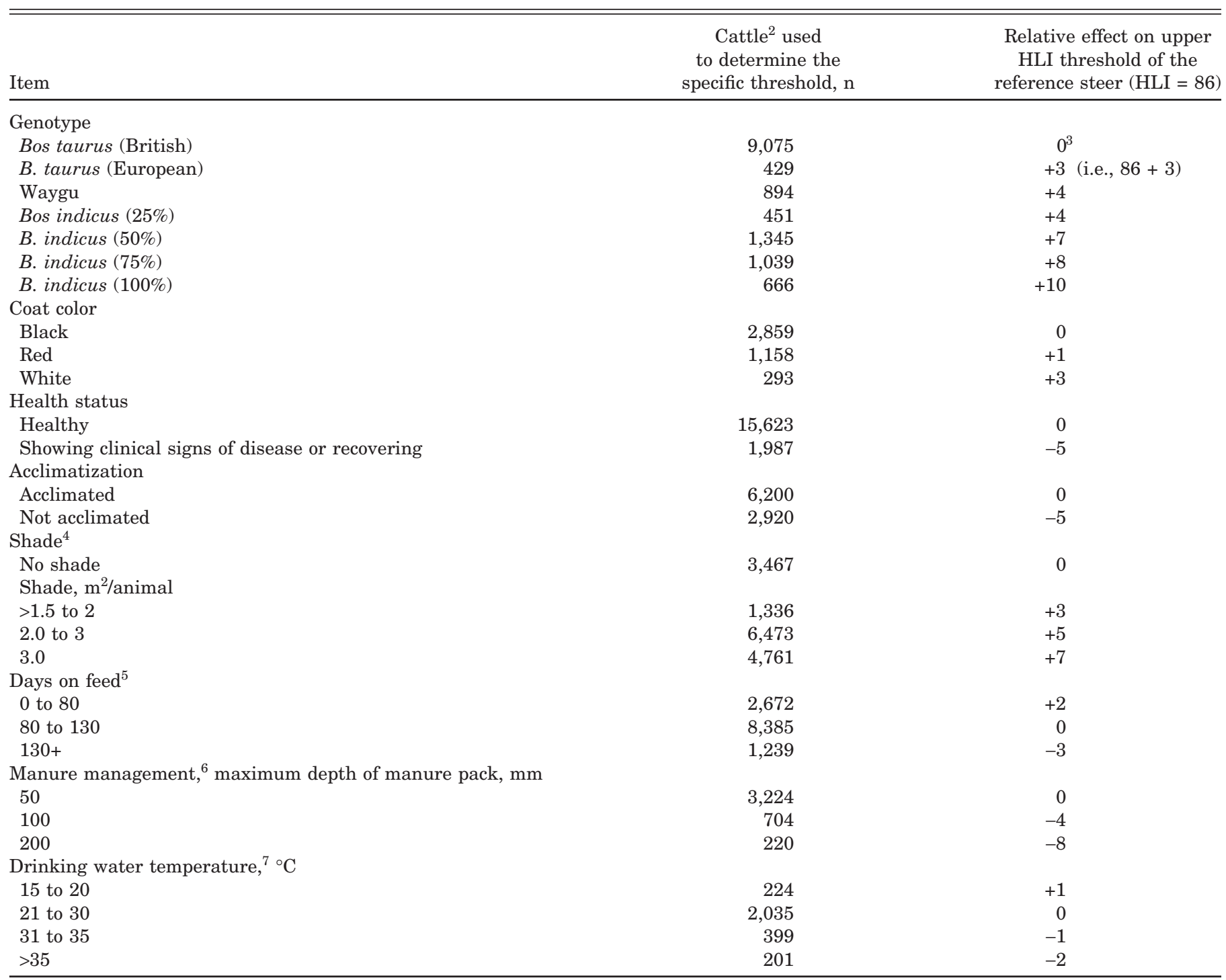

${ }^{1} \mathrm{~A}$ healthy, unshaded Angus at $100 \mathrm{~d}$ on feed.

${ }^{2}$ Not all cattle were assessed within each threshold trait. For example, coat color was assessed only in B. taurus cattle, manure management was assessed at 5 feedlots, and drinking water temperature was assessed on 3 feedlots.

${ }^{3}$ The values for the reference steer are presented as 0 (i.e., no change from the threshold of 86).

${ }^{4}$ For shade that provides $70 \%$ blockout (includes shade cloth and also steel structures with gaps in the roof). Unshaded B. indicus cattle $>25 \%$ were not included.

${ }^{5}$ Not all cattle were assessed for this trait. Waygu cattle were excluded from $130+\mathrm{d}$.

${ }^{6}$ Mean depth over $54 \mathrm{~d}$.

${ }^{7}$ Only unshaded Angus cattle were assessed for this trait.

reference animal); $\mathrm{HLI}_{\text {Upper Threshold }}=$ the HLI threshold above which cattle in a particular class will gain heat (e.g., 86 for the reference animal); and $\mathrm{M}=$ measures per hour (i.e., how often HLI data are collected per hour). If every $10 \mathrm{~min}$, then $\mathrm{M}=6$.

\section{Development of Threshold Adjustments}

The critical HLI threshold value of 86 was determined based on panting score observations $(\mathrm{n}=4,200)$ of unshaded Angus steers. However, the HLI value at which body heat is dissipated into the environment is influenced by a number of factors, including, but not limited to, genotype, coat color, health status, degree of acclimatization, and access to shade. The influence of the previously mentioned factors on alleviating or contributing to heat load was assessed primarily based on changes in mean panting score. Adjustments (either positive or negative) were made on the basis of $\geq 20 \%$ of cattle in a pen having a panting score of $\geq 1$. Adjustments to the reference threshold were made and new thresholds for the different management strategies and genotypes observed were developed (Table 2). A positive value indicates that the threshold has been increased, 
Table 3. Panting scores (\%) for 6 genotypes when the heat load index (HLI) was categorized as thermoneutral (TNC), warm, hot, or very hot

\begin{tabular}{|c|c|c|c|c|c|c|c|}
\hline \multirow[b]{2}{*}{ Genotype } & \multirow[b]{2}{*}{$\mathrm{HLI}^{1,2}$} & \multicolumn{6}{|c|}{ Panting score ${ }^{3}$} \\
\hline & & 0 & 1 & 2 & 2.5 & 3 & $\geq 3.5$ \\
\hline \multirow[t]{4}{*}{ Angus, shade $(\mathrm{n}=4,210)$} & TNC & $92.96^{\mathrm{a}}$ & $6.65^{\mathrm{a}}$ & $0.36^{\mathrm{a}}$ & 0.03 & 0 & 0 \\
\hline & Warm & $83.31^{\mathrm{a}}$ & $13.66^{\mathrm{a}}$ & $2.89^{\mathrm{a}}$ & $0.14^{\mathrm{a}}$ & $<0.01$ & 0 \\
\hline & Hot & $74.92^{\mathrm{a}}$ & $23.41^{\mathrm{a}}$ & $1.61^{\mathrm{a}}$ & $0.06^{\mathrm{a}}$ & $0^{\mathrm{a}}$ & $0^{\mathrm{a}}$ \\
\hline & Very hot & $43.91^{\mathrm{a}}$ & $37.77^{\mathrm{a}}$ & $14.46^{\mathrm{a}}$ & $3.12^{\mathrm{a}}$ & $0.68^{\mathrm{a}}$ & $0.06^{\mathrm{a}}$ \\
\hline \multirow[t]{4}{*}{ Angus, no shade $(\mathrm{n}=2,859)$} & TNC & $89.41^{\mathrm{a}}$ & $10.11^{\mathrm{a}}$ & $0.48^{\mathrm{a}}$ & 0 & 0 & 0 \\
\hline & Warm & $55.11^{\mathrm{c}}$ & $32.68^{\mathrm{c}}$ & $11.21^{\mathrm{a}}$ & $1.0^{\mathrm{a}}$ & 0 & 0 \\
\hline & Hot & $47.62^{\mathrm{c}}$ & $11.16^{\mathrm{c}}$ & $21.22^{\mathrm{a}}$ & $13.22^{\mathrm{b}}$ & $3.00^{\mathrm{b}}$ & $3.78^{b}$ \\
\hline & Very hot & $33.91^{\mathrm{a}}$ & $28.00^{\mathrm{b}}$ & $19.09^{\mathrm{a}}$ & $16.00^{\mathrm{b}}$ & $1.00^{\mathrm{a}}$ & $2.00^{b}$ \\
\hline \multirow[t]{4}{*}{ Brahman, shade $(\mathrm{n}=657)$} & TNC & $100.00^{\mathrm{b}}$ & $0^{\mathrm{b}}$ & $0^{\mathrm{b}}$ & 0 & 0 & 0 \\
\hline & Warm & $99.99^{b}$ & $0.01^{\mathrm{b}}$ & $0^{\mathrm{b}}$ & 0 & 0 & 0 \\
\hline & Hot & $99.42^{\mathrm{b}}$ & $0.58^{b}$ & $0^{\mathrm{b}}$ & 0 & 0 & 0 \\
\hline & Very hot & $99.09^{\mathrm{d}}$ & $0.91^{\mathrm{d}}$ & $0^{\mathrm{b}}$ & $0^{\mathrm{b}}$ & 0 & 0 \\
\hline \multirow{4}{*}{ Brahman, no shade $(\mathrm{n}=746)$} & TNC & $99.84^{\mathrm{b}}$ & $0.16^{\mathrm{b}}$ & $0^{\mathrm{b}}$ & 0 & 0 & 0 \\
\hline & Warm & $99.60^{\mathrm{b}}$ & $0.40^{\mathrm{b}}$ & $0^{\mathrm{b}}$ & 0 & 0 & 0 \\
\hline & Hot & $99.12^{\mathrm{b}}$ & $0.88^{b}$ & $0^{\mathrm{b}}$ & 0 & 0 & 0 \\
\hline & Very hot & $79.69^{b}$ & $19.55^{\mathrm{b}}$ & $0.64^{\mathrm{b}}$ & $0.09^{b}$ & 0.03 & 0 \\
\hline \multirow[t]{4}{*}{ Hereford, shade $(\mathrm{n}=612)$} & TNC & $88.55^{\mathrm{a}}$ & $11.44^{\mathrm{a}}$ & $0.01^{\mathrm{b}}$ & 0 & 0 & 0 \\
\hline & Warm & $49.37^{\mathrm{c}}$ & $44.22^{\mathrm{c}}$ & $6.13^{\mathrm{a}}$ & 0.28 & 0 & 0 \\
\hline & Hot & $42.06^{\mathrm{c}}$ & $43.31^{\mathrm{c}}$ & $13.68^{\mathrm{b}}$ & $0.82^{\mathrm{a}}$ & 0.14 & 0 \\
\hline & Very hot & $19.47^{\mathrm{c}}$ & $54.31^{\mathrm{c}}$ & $23.21^{\mathrm{c}}$ & $2.69^{\mathrm{a}}$ & 0.32 & 0 \\
\hline \multirow[t]{4}{*}{ Brahman $\times$ Hereford, no shade $(\mathrm{n}=608)$} & TNC & $100.00^{\mathrm{b}}$ & $0^{\mathrm{b}}$ & $0^{\mathrm{b}}$ & 0 & 0 & 0 \\
\hline & Warm & $100.00^{\mathrm{b}}$ & $0^{\mathrm{d}}$ & $0^{\mathrm{b}}$ & 0 & 0 & 0 \\
\hline & Hot & $99.81^{b}$ & $0.19^{\mathrm{b}}$ & $0^{\mathrm{b}}$ & 0 & 0 & 0 \\
\hline & Very hot & $96.39^{\mathrm{d}}$ & $3.61^{\mathrm{d}}$ & $0^{\mathrm{d}}$ & $0^{b}$ & 0 & 0 \\
\hline \multirow{4}{*}{ Angus $\times$ Hereford, shade $(\mathrm{n}=704)$} & TNC & $89.52^{\mathrm{a}}$ & $10.37^{\mathrm{a}}$ & $0.08^{b}$ & 0.03 & 0 & 0 \\
\hline & Warm & $78.52^{\mathrm{d}}$ & $21.34^{\mathrm{a}}$ & $0.14^{\mathrm{c}}$ & 0 & 0 & 0 \\
\hline & Hot & $60.03^{\mathrm{d}}$ & $39.84^{\mathrm{c}}$ & $0.13^{\mathrm{c}}$ & 0 & 0 & 0 \\
\hline & Very hot & $35.30^{\mathrm{a}}$ & $53.58^{\mathrm{c}}$ & $8.68^{\mathrm{e}}$ & $2.07^{\mathrm{a}}$ & 0.34 & 0.03 \\
\hline \multirow[t]{4}{*}{ Waygu, shade $(\mathrm{n}=894)$} & TNC & $98.90^{\mathrm{b}}$ & $1.1^{\mathrm{b}}$ & $0^{\mathrm{b}}$ & 0 & 0 & 0 \\
\hline & Warm & $100.00^{\mathrm{b}}$ & $0^{\mathrm{d}}$ & $0^{\mathrm{b}}$ & 0 & 0 & 0 \\
\hline & Hot & $97.87^{\mathrm{b}}$ & $2.13^{\mathrm{d}}$ & $0^{\mathrm{b}}$ & 0 & 0 & 0 \\
\hline & Very hot & $94.12^{\mathrm{d}}$ & $5.88^{\mathrm{d}}$ & $0^{\mathrm{d}}$ & $0^{c}$ & 0 & 0 \\
\hline
\end{tabular}

${ }^{\mathrm{a}-\mathrm{e}}$ Means in a column within an HLI category (i.e., Hot only compared with Hot) with the same superscript were not different $(P>0.05)$. Where significant, all $P$-values were $<0.01$. If no superscripts are shown, there was insufficient data to undertake analysis.

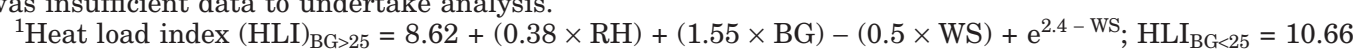
$+(0.28 \times \mathrm{RH})+(1.3 \times \mathrm{BG})-\mathrm{WS}$.

${ }^{2}$ TNC, HLI $<70$; warm, HLI $>70<77$; hot, HLI $>77<86$; very hot, HLI $>86$.

${ }^{3}$ Cattle with a panting score $>1$ were considered to be stressed.

and a negative value indicates that the threshold has been reduced. For example, the HLI threshold for purebred $B$. indicus is $96(86+10)$. The threshold for these animals may be greater than 96 ; however, there were not sufficient data where HLI > 95 .

\section{Relationships Among Mean Panting Score, $H L I$, and $A H L$}

Effects of the HLI category on the panting scores of 6 genotypes are presented in Table 3. Both HLI and AHL had an effect $(P<0.001)$ on mean panting score. The $\mathrm{R}^{2}$ were high, at 0.93 and 0.92 for HLI and AHL, respectively. The $\mathrm{R}^{2}$ for THI was $0.6(P<0.001)$, and was $0.37(P<0.001)$ for THI-hours. The HLI $\times$ AHL interactions were a good predictor $\left(P<0.001 ; \mathrm{R}^{2}=0.92\right)$ of panting score (all genotypes) when pen within feedlot and feedlot location were considered. The effects of the
HLI $\times$ AHL on Angus and Brahman steers are presented in Figure 1.

The Brahman cattle were less affected than Angus by the HLI and AHL encountered (Figure 1). Nevertheless, they were not immune to extreme conditions. Increased panting scores were observed when the AHL exceeded 10 and the HLI was greater than 86. However, the percentage of Brahman with a panting score of 0 was higher $(P<0.05)$ when compared with Angus exposed to similar climatic conditions.

\section{Tympanic Temperature}

The relationship between tympanic temperature and the average HLI for the previous $24 \mathrm{~h}$ was moderate $\left(\mathrm{R}^{2}=0.67 ; P<0.001\right)$, and was considerably better than the relationship between tympanic temperature and THI $\left(\mathrm{R}^{2}=0.26 ; P<0.001\right)$. A linear model was developed 


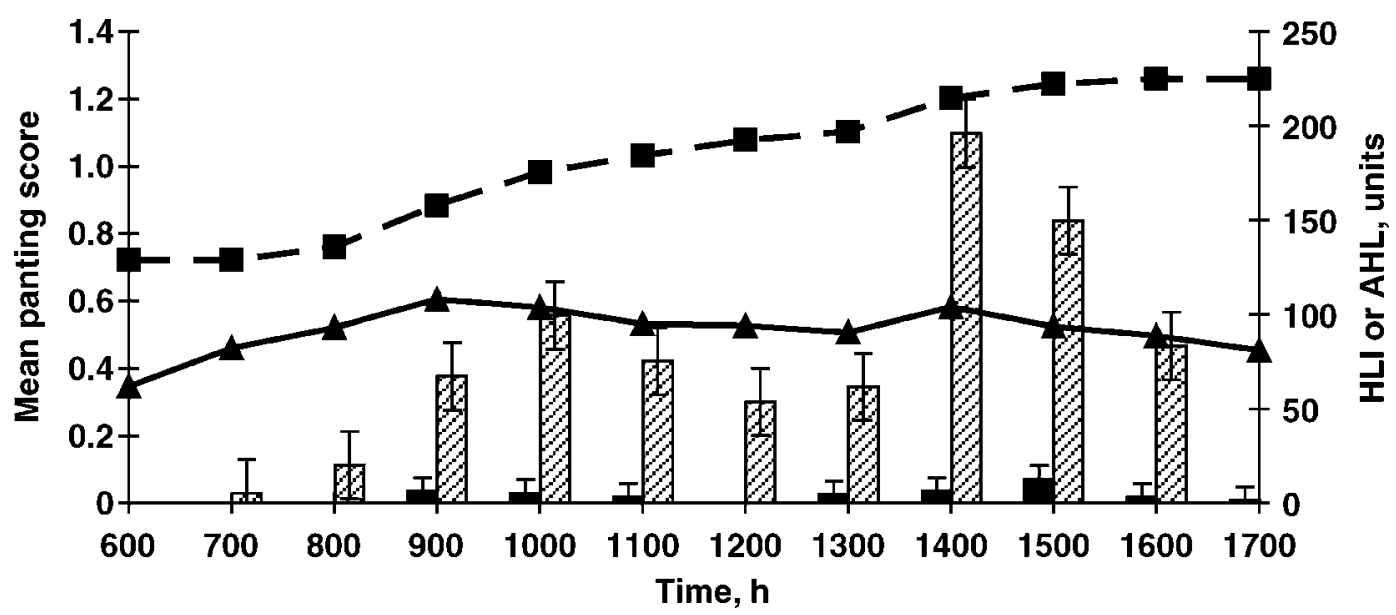

Figure 1. The mean hourly panting score of unshaded Angus steers (striped bars) and unshaded Brahman steers (solid bars), and the mean hourly heat load index (HLI, A) and accumulated heat load (AHL, $\mathbf{\square})$ between 0600 and 1700 on a day classified as very hot $\left(\mathrm{HLI}>86\right.$, AHL > 50). $\mathrm{HLI}_{\mathrm{BG}>25}=8.62+(0.38 \times \mathrm{RH})+(1.55 \times \mathrm{BG})-(0.5 \times \mathrm{WS})$ $+\mathrm{e}^{2.4-W S} ; \mathrm{HLI}_{\mathrm{BG}<25}=10.66+(0.28 \times \mathrm{RH})+(1.3 \times \mathrm{BG})-\mathrm{WS}$. The AHL is a 2-dimensional function incorporating time and animal heat balance; that is, the amount of time the animal is exposed to an HLI above a threshold (the threshold for an unshaded Angus steer is 86).

for tympanic temperature by using time and the average HLI over the previous $24 \mathrm{~h}$ (equation [7]):

$$
\begin{gathered}
\mathrm{TT}=37.12-0.45 \times \sin \mathrm{T}+0.09 \times \cos \mathrm{T} \\
+0.13 \times \sin ^{2} \mathrm{~T}-\cos ^{2} \mathrm{~T} \times 0.02+0.03 \times \mathrm{HLI}_{24}
\end{gathered}
$$

where $\mathrm{TT}=$ tympanic temperature; $\mathrm{T}=$ hour of the day in half-hour increments $(1300=13,1330=13.5,0100=$ 1 ); and $\mathrm{HLI}_{24}=$ the average HLI over the previous $24 \mathrm{~h}$.

\section{DISCUSSION}

High heat load in feedlot cattle is a result of local climatic conditions and animal factors that lead to an increase in body heat content beyond the animal's normal physiological range and its ability to cope. By using a combination of observed local climatic conditions and animal responses to the climate (panting scores), feedlot managers will be able to implement strategies to reduce the impact of severe hot weather conditions.

Development of a thermal stress index for cattle should be based on biological factors (Nienaber et al., 1999; Hahn et al., 2003). The need for a large data set to develop and test an index necessitates that the biological parameter used must be easy to measure and be a good indicator of heat load. Behavioral changes are reliable indicators of heat load status. Feedlot location, feedlot layout, and pen microclimate influence the behavior of cattle (Castaňeda et al., 2004). However, measuring climatic conditions within pens is difficult and is not practical under most conditions. Therefore, the location of a weather station at a feedlot needs to be representative of the average climatic conditions to which cattle are exposed. Changes in DMI when cattle are exposed to hot conditions are well documented
(NRC, 1981; Roseler et al., 1997; Holt et al., 2004). However, on its own DMI is not a good indicator of heat load status. Body temperature and respiration rate are reliable indicators of heat load but are difficult to measure under field conditions (Hahn et el., 1997; Gaughan et al., 2000; Gaughan et al., 2002; Brown-Brandl et al., 2005a), especially where large numbers of animals are involved. An alternative method is the use of panting scores (Mader et al., 2001). Panting scores have been used to evaluate the heat load status of feedlot cattle under commercial and research conditions, and are a reliable indicator of heat load status (Mader et al., 2001, 2006; Davis et al., 2001; Gaughan et al., 2002, 2004; Brown-Brandl et al., 2006). In the current study, panting scores served as the basis for the development of the HLI.

There are temperature thresholds above which respiration rate and panting score increase. The thresholds are somewhat genotype specific. Threshold values are defined as the climatic values, in this case HLI values, that trigger a response (Hahn et al., 1992; St-Pierre et al., 2003). In the current study, a threshold of $25^{\circ} \mathrm{C}$ (BG temperature) was determined for increasing respiration rates. A lower value $\left(21^{\circ} \mathrm{C}\right.$; dry bulb temperature) was reported by Brown-Brandl et al. (2006). Similar threshold values for respiration rate have been reported by Hahn et al. (1997; $21^{\circ} \mathrm{C}$; dry bulb temperature) and Eigenberg et al. (2005) with a threshold range of 25 to $30^{\circ} \mathrm{C}$ (dry bulb temperature).

Cattle adjust physiologically, behaviorally, and immunologically to minimize the adverse effects of thermal stress (Johnson, 1987; Hahn, 1999). Factors such as nutrition (Hahn et al., 1990; Hahn and Nienaber, 1993; Mader et al., 1999a; Mader et al., 2001; Gaughan et al., 2004; Holt et al., 2004), health status (MorrowTesch and Hahn, 1994; Brown-Brandl et al., 2006), BCS 
(Brown-Brandl et al., 2006), genotype or phenotype (Hammond et al., 1996, 1998; Gaughan et al., 1999; Brown-Brandl et al., 2006), magnitude of exposure (Hahn and Mader, 1997), and housing (Mader et al., 1999b; Mitlöhner et al., 2001) affect the responses of cattle when faced with a thermal challenge. Development of a predictive model that takes into account all the factors that are likely to affect heat tolerance is difficult (Nienaber et al., 1999). The HLI model can explain $93 \%$ of the variation in panting score and is a good predictor of the thermal status of various genotypes. As expected, British breeds (Angus and Hereford) had lower heat tolerance than Brahman and Waygu (Table 3). The percentage of cattle with a panting score of 0 decreased (more cattle had elevated panting scores) as the HLI categories moved through each stage from thermoneutral to very hot, except for Brahman and Waygu, where the percentage did not decrease until the very hot conditions were encountered. These data show that there are differences between genotypes; therefore, a single value to predict or measure the impact of heat stress is not valid.

The existing indices (THI) use a 1-dimensional approach, the thermal situation at a point in time (intensity only). They do not take into account the effect of exposure (duration) to adverse thermal conditions. Furthermore, there is no genotype distinction, so all cattle are assumed to respond the same. As such, THI may under- or overestimate the effect of an adverse heat event, especially if nighttime conditions are not considered. Nighttime recovery (or a lack thereof) is an important element when assessing the heat load status of cattle (Hahn and Mader, 1997). If nighttime conditions are not considered, the heat load status of cattle may be underestimated. If the day following a heat event is cool, then underestimation is not critical. However, if the following day is hot (HLI > threshold), then cattle may enter the day with a carryover heat load and may be susceptible to heat stress at lower HLI values than expected. In addition, Hahn et al. (1997) and Gaughan et al. (2000) reported that respiration rate may lag behind dry bulb temperature by up to 3 $\mathrm{h}$ when cattle are housed in climate chambers. A lag of $1 \mathrm{~h}$ for cattle housed in a feedlot was reported by Brown-Brandl et al. (2005a). It is clear that current ambient conditions may not have an immediate impact on the animal.

On a daily basis, cattle may be subjected to an HLI greater than 86 and yet have an AHL of less than 1 . In addition, cattle may be exposed to an HLI of less than 70 but have an AHL greater than 50. In both cases, panting score will be elevated for $B$. taurus cattle (Figure 1). Cattle observed in the afternoon of a hot day continue to have elevated panting scores even if the HLI has decreased below the threshold, especially where they have considerable accumulated heat. This comes about because the cattle have not had sufficient time to offload the excessive heat gained during the day.
In conclusion, development of a dynamic thermal index will improve animal management during periods of adverse weather. The AHL model takes into account the magnitude of exposure (intensity $\times$ duration), the genotype or phenotype, coat color, the degree of acclimatization, and access to shade. The AHL index can be adjusted (by feedlot management) by using thresholds based on animal responses to observed conditions. Adjustments can be made on a pen by pen basis if required (newly arrived cattle vs. cattle at $150 \mathrm{~d}$ on feed). An on-site weather station will improve the accuracy of the HLI and AHL for a particular site.

The HLI and AHL have been incorporated into a Webbased heat load model (www.katestone.com.au) that allows feedlot managers to input their location, cattle type, days on feed, health status, and heat alleviation strategies, such as shade and manure management. Based on these inputs, a heat risk assessment is calculated. The model uses historical weather data for the specified locations. However, potential risk can also be calculated by using current weather conditions. A 6 -d forecast is also provided. The model is dynamic and, as results from future studies involving both beef and dairy cattle and feedback from users are obtained, adjustments will be made.

\section{LITERATURE CITED}

Baeta, F. C., N. F. Meador, M. D. Shanklin, and H. D. Johnson. 1987. Equivalent temperature index at temperatures above thermoneutral for lactating dairy cows. ASAE Meeting Paper 874015. Am. Soc. Agric. Eng., St. Joseph. MI.

Brown-Brandl, T. M., R. A. Eigenberg, and J. A. Nienaber. 2006. Heat stress risk factors for feedlot heifers. Livest. Sci. 105:57-68.

Brown-Brandl, T. M., R. A. Eigenberg, J. A. Nienaber, and G. L. Hahn. 2005a. Dynamic response indicators of heat stress in shaded and non-shaded feedlot cattle, Part 1: Analysis of indicators. Biosys. Eng. 90:451-462.

Brown-Brandl, T. M., D. D. Jones, and W. E. Woldt. 2005b. Evaluating modelling techniques for cattle heat stress prediction. Biosys. Eng. 91:513-524.

Buffington, D. E., A. Colazon-Arocho, G. H. Canton, and D. Pitt. 1981. Black globe-humidity index (BGHI) as comfort equation for dairy cows. Trans. Am. Soc. Agric. Eng. 24:711-714.

Castaňeda, C. A., J. B. Gaughan, and Y. Sakaguchi. 2004. Relationships between climatic conditions and the behaviour of feedlot cattle. Anim. Prod. Aust. 25:33-36.

Davis, S., T. Mader, S. Holt, and W. Cerkoney. 2001. Effects of feeding regime on performance, behavior and body temperature of feedlot steers. Pages 69-73 in 2001 Nebraska Beef Report. University of Nebraska, Lincoln.

Eigenberg, R. A., T. M. Brown-Brandl, J. A. Nienaber, and G. L. Hahn. 2005. Dynamic response indicators of heat stress in shaded and non-shaded feedlot cattle, Part 2: Predictive relationships. Biosys. Eng. 91:111-118.

Gaughan, J. B., M. S. Davis, and T. L. Mader. 2004. Wetting and the physiological responses of grain-fed cattle in a heated environment. Aust. J. Agric. Res. 55:253-260.

Gaughan, J. B., S. M. Holt, G. L. Hahn, T. L. Mader, and R. Eigenberg. 2000. Respiration rate-Is it a good measure of heat stress in cattle? Asian-Australas. J. Anim. Sci. 13:329-332.

Gaughan, J. B., T. L. Mader, S. M. Holt, G. L. Hahn, and B. A. Young. 2002. Review of current assessment of cattle and microclimate during periods of high heat load. Anim. Prod. Aus. 24:77-80. 
Gaughan, J. B., T. L. Mader, S. M. Holt, M. J. Josey, and K. Rowan. 1999. Heat tolerance of Boran and Tuli crossbred steers. J. Anim. Sci. 77:2398-2405.

Hahn, G. L. 1999. Dynamic responses of cattle to thermal heat loads. J. Anim. Sci. 77(Suppl. 2):10-12.

Hahn, G. L., Y. R. Chen, J. A. Nienaber, R. A. Eigenberg, and A. M. Parkhurst. 1992. Characterizing animal stress through fractal analysis of thermoregulatory responses. J. Therm. Biol. $17: 115-120$

Hahn, G. L., R. A. Eigenberg, J. A. Nienaber, and E. T. Littledike. 1990. Measuring physiological responses of animals to environmental stressors using a microcomputer-based portable datalogger. J. Anim. Sci. 68:2658-2665.

Hahn, G. L., and T. L. Mader. 1997. Heat waves in relation to thermoregulation, feeding behaviour and mortality of feedlot cattle. Pages 563-571 in Proc. 5th Int. Livest. Environ. Symp., Bloomington, MN. R. W. Bottcher and S. J. Hoff, ed. Am. Soc. Agric. Eng., St. Joseph, MI.

Hahn, G. L., T. L. Mader, and R. A. Eigenberg. 2003. Perspective on development of thermal indices for animal studies and management. Pages 31-44 in Interactions Between Climate and Animal Production. EAAP Technical Series No. 7. Wageningen Academic Publishers, the Netherlands.

Hahn, G. L. and J. A. Nienaber. 1993. Characterizing stress in feeder cattle. Pages 146-148 in Beef Res. Progr. Rep. No. 4 (ARS-71), US Meat Anim. Res. Center, ARS, USDA, Clay Center, NE.

Hahn, G. L., A. M. Parkhurst, and J. B. Gaughan. 1997. Cattle respiration rate as a function of ambient temperature. ASAE Paper No. MC97-121. Am. Soc. Agric. Eng., St. Joseph, MI.

Hammond, A. C., C. C. Chase, E. J. Bowers, T. A. Olson, and R. D. Randel. 1998. Heat tolerance of Tuli-, Senepol-, and Brahmansired $\mathrm{F}_{1}$ Angus heifers in Florida. J. Anim. Sci. 76:1568-1577.

Hammond, A. C., T. A. Olson, C. C. Chase, E. J. Bowers, R. D. Randel, C. N. Murphy, D. W. Vogt, and A. Tewolde. 1996. Heat tolerance of in two tropically adapted Bos taurus breeds, Senepol and Romosinauno, compared with Brahman, Angus, and Hereford cattle in Florida. J. Anim. Sci. 74:295-303.

Holt, S. M., J. B. Gaughan, and T. L. Mader. 2004. Feeding strategies for grain-fed cattle in a hot environment. J. Agric. Res. 55:719-725.

Ibrahim, M. N., D. G. Stevens, M. D. Shanklin, and G. L. Hahn. 1975. Model of broiler performance as affected by temperature and humidity. Trans. Am. Soc. Agric. Eng. 18:960-962.
Ingraham, R. H., D. D. Gillette, and W. D. Wagner. 1974. Relationship of temperature and humidity to conception rate of Holstein cows in subtropical climate. J. Dairy Sci. 57:476-481.

Johnson, H. D. 1987. Bioclimate effects on growth, reproduction and milk production. Pages 35-57 in Bioclimatology and the Adaptation of Livestock. World Anim. Sci. B5. Elsevier, Amsterdam, the Netherlands.

Livestock Conservation Incorporated. 1970. Patterns of Transient Losses. Livest. Conserv. Inc., Omaha, NE.

Mader, T. L., J. M. Dahlquist, G. L. Hahn, and J. B. Gaughan. 1999a. Shade and wind barrier effects on summertime feedlot cattle performance. J. Anim. Sci. 77:2065-2072.

Mader, T. L., M. S. Davis, and T. Brown-Brandl. 2006. Environmental factors influencing heat stress in feedlot cattle. J. Anim. Sci. 84:712-719.

Mader, T. L., J. B. Gaughan, and B. A. Young. 1999b. Feedlot diet roughage level for Hereford cattle exposed to excessive heat load. Prof. Anim. Sci. 15:53-62.

Mader, T. L., S. M. Holt, G. L. Hahn, M. S. Davis, and D. E. Spiers. 2002. Feeding strategies for managing heat load in feedlot cattle. J. Anim. Sci. 80:2373-2382.

Mader, T., S. Holt, T. Scott, and S. Davis. 2001. Restricted feeding strategies for reducing heat load of yearling steers. Pages 7477 in 2001 Nebraska Beef Rep. Univ. Nebraska, Lincoln.

Mitlöhner, F. M., J. L. Morrow, D. W. Daily, S. C. Wilson, M. L. Galyean, M. F. Miller, and J. J. McGlone. 2001. Shade and water misting effects on behaviour, physiology, performance, and carcass traits of heat-stressed feedlot cattle. J. Anim. Sci. 79:2327-2335.

Morrow-Tesch, J., and G. L. Hahn. 1994. Immune responses of cattle to thermal stress. ASAE Paper No. 944021. Am. Soc. Agric. Eng., St. Joseph, Minneapolis, MI.

Nienaber, J. A., G. L. Hahn, and R. A. Eigenberg. 1999. Quantifying livestock responses for heat stress management: A review. Int. J. Biometeorol. 42:183-188.

NRC. 1981. Effect of Environment on Nutrient Requirements of Domestic Animals. Natl. Acad. Sci., Washington, DC

Roseler, D. K., D. G. Fox, L. E. Chase, A. N. Pell, and W. C. Stone. 1997. Development and evaluation of equations for prediction of feed intake for lactating Holstein dairy cows. J. Dairy Sci. $80: 878-893$

St-Pierre, N. R., B. Cobanov, and G. Schnitkey. 2003. Economic losses from heat stress by US livestock industries. J. Dairy Sci. 86(ESuppl.):E52-E77.

Thom, E. C. 1959. The discomfort index. Weatherwise 12:57-59. 